\title{
The influence of rhizosphere soil fungal diversity and complex community structure on wheat root rot disease
}

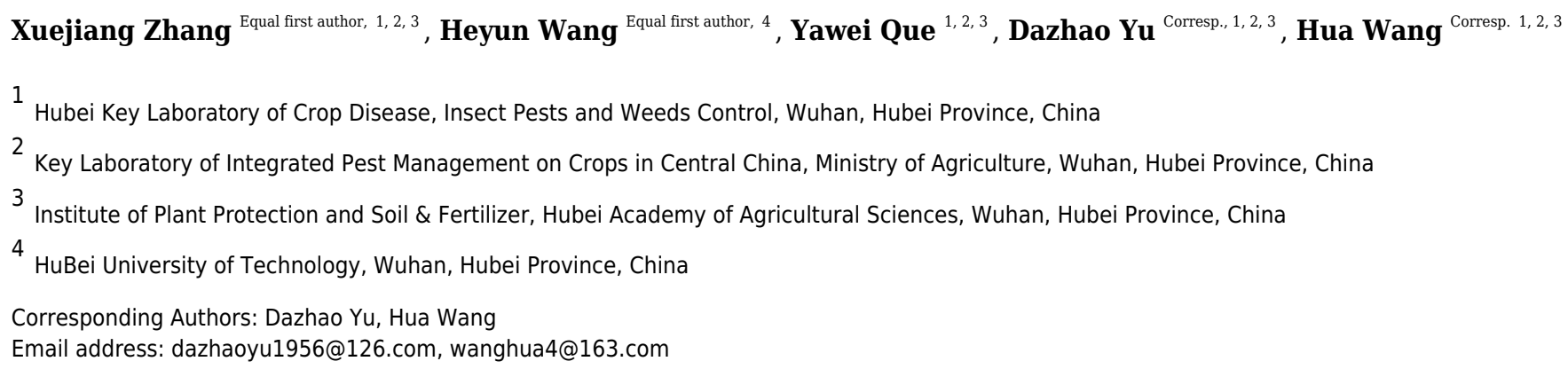

Wheat root rot disease due to soil-borne fungal pathogens leads to tremendous yield losses worth billions of dollars worldwide every year. It is very important to study the relationship between rhizosphere soil fungal diversity and wheat roots to understand the occurrence and development of wheat root rot disease. A significant difference in fungal diversity was observed in the rhizosphere soil of healthy and diseased wheat roots in the heading stage, but the trend was the opposite in the filling stage. The abundance of most genera with high richness decreased significantly from the heading to the filling stage in the diseased groups; the richness of approximately one-third of all genera remained unchanged, and only a few low-richness genera, such as Fusarium and Ceratobasidium, had a very significant increase from the heading to the filling stage. In the healthy groups, the abundance of most genera increased significantly from the heading to the filling stage; the abundance of some genera did not change markedly, or the abundance of very few genera increased significantly. Physical and chemical soil indicators showed that low soil $\mathrm{pH}$ and density, increases in ammonium nitrogen, nitrate nitrogen and total nitrogen contributed to the occurrence of wheat root rot disease. Our results revealed that in the early stages of disease, highly diverse rhizosphere soil fungi and a complex community structure can easily cause wheat root rot disease. The existence of pathogenic fungi is a necessary condition for wheat root rot disease, but the richness of pathogenic fungi is not necessarily important. The increases in ammonium nitrogen, nitrate nitrogen and total nitrogen contributed to the occurrence of wheat root rot disease. Low soil pH and soil density are beneficial to the occurrence of wheat root rot disease. 
2 The Influence of Rhizosphere Soil Fungal Diversity and Complex Community 3 Structure on Wheat Root Rot Disease

4 Xuejiang Zhang ${ }^{1,2,3, \#}$, Heyun Wang ${ }^{4, \#}$, Yawei Que ${ }^{1,2,3}$, Dazhao Yu ${ }^{1,2,3,{ }^{*}}$, Hua Wang ${ }^{1,2,3, *}$ 5

$6{ }^{1}$ Institute of Plant Protection and Soil \& Fertilizer, Hubei Academy of Agricultural Sciences, 7 Wuhan, Hubei Provience, P. R. China

$82^{2}$ Key Laboratory of Integrated Pest Management on Crops in Central China, Ministry of 9 Agriculture, Wuhan, Hubei Provience, P. R. China

${ }^{3}$ Hubei Key Laboratory of Crop Disease, Insect Pests and Weeds Control, Wuhan, Hubei

11 Provience, P. R. China

${ }^{4}$ HuBei University of Technology, Wuhan, Hubei Provience, P. R. China

13

1,2,3,\# Xuejiang Zhang

zhangxuejiang1976@126.com

4,\# Heyun Wang

heyunwang2006@163.com

1,2,3 Yawei Que

queyawei@126.com

\section{Co-corresponding authors:}

$1,2,3,{ }^{*}$ Hua Wang

wanghua4@163.com

1,2,3, ${ }^{*}$ Dazhao $\mathrm{Yu}$

dazhaoyu1956@126.com

\# The author Heyun Wang contributed equally to this work. 


\section{ABSTRACT}

Wheat root rot disease due to soil-borne fungal pathogens leads to tremendous yield losses worth billions of dollars worldwide every year. It is very important to study the relationship between rhizosphere soil fungal diversity and wheat roots to understand the occurrence and development of wheat root rot disease. A significant difference in fungal diversity was observed in the rhizosphere soil of healthy and diseased wheat roots in the heading stage, but the trend was the opposite in the filling stage. The abundance of most genera with high richness decreased significantly from the heading to the filling stage in the diseased groups; the richness of approximately one-third of all genera remained unchanged, and only a few low-richness genera, such as Fusarium and Ceratobasidium, had a very significant increase from the heading to the filling stage. In the healthy groups, the abundance of most genera increased significantly from the heading to the filling stage; the abundance of some genera did not change markedly, or the abundance of very few genera increased significantly. Physical and chemical soil indicators showed that low soil $\mathrm{pH}$ and density, increases in ammonium nitrogen, nitrate nitrogen and total nitrogen contributed to the occurrence of wheat root rot disease. Our results revealed that in the early stages of disease, highly diverse rhizosphere soil fungi and a complex community structure can easily cause wheat root rot disease. The existence of pathogenic fungi is a necessary condition for wheat root rot disease, but the richness of pathogenic fungi is not necessarily important. The increases in ammonium nitrogen, nitrate nitrogen and total nitrogen contributed to the occurrence of wheat root rot disease. Low soil $\mathrm{pH}$ and soil density are beneficial to the occurrence of wheat root rot disease.

Keywords: Rhizosphere soil, Fungal diversity, Community structure, Wheat root rot disease

\section{INTRODUCTION}

Soil microbial diversity is important to sustainable agriculture because microbes mediate many processes that are essential to the agricultural productivity of soil (Lupwayi et al., 1998). However, to meet the food demand of an increasing population, intensive agricultural practices 
57 and excessive cultivation of crops have destroyed soil structure and ignored the biological potential of roots or rhizospheres to efficiently mobilize and acquire soil nutrients (Parkinson and Coleman, 1981; Schreiner and Bethlenfalvay, 1996; Assaf et al., 2009; Kumar and Pratush, 2014; Taheri et al., 2015; Ai et al., 2015; Rashida et al., 2016). As such, soils have very low biological activity, and plants growing in these soils are predisposed to soil-borne pathogens (Sivasithamparam, 1993; Kirkegard et al. 2008; Wintera et al., 2014; Almasudy et al., 2015).

With the destruction of soil structure, the degradation of soil and the increase in soil-borne pathogens, wheat, as one of the three major staple foods in the world, grown in Asia (China), Australia, Europe, North America, and South America, is vulnerable to attack by a complex of root pathogens, which results in tremendous yield losses (Duffy, 2000). Annual losses in wheat industries due to soil-borne fungal pathogens amount to over billions of dollars worldwide (Paulitz et al., 2002; Mavrodi et al., 2012; Okubara et al., 2014). All cultivars of wheat are attacked by several soil-borne fungal pathogens that cause root diseases (Mavrodi et al., 2012). The primary fungal pathogens include the following: Fusarium culmorum, $F$. pseudograminearum, Gaeumannomyces graminis var. Tritici, Bipolaris sorokiniana, and Alternaria spp. in Ascomycota; Rhizopus oryzae, Rhizoctonia solani and Penicillium spp. in Basidiomycota; Pythium spp. in Oomycota; and Curvularia spp. in Deuteromycota (Mielke, 1998; Wintera et al., 2014). Root diseases are difficult to control because these soil-borne fungi are ubiquitous, the pathogens often occur as a complex (Paulitz and Adams, 2003; Mavrodi et al., 2012), and they can easily survive on infected plant debris or form durable chlamydospores in the soil with or in the absence of growing hosts and can outgrow or evade plant defenses (Smith et al., 2013; Wintera et al., 2014). There are no resistant varieties among adapted cultivars of wheat and no chemical controls, although certain seed treatments can provide some early benefits to seedling health (Paulitz and Scott, 2006; Davis et al., 2008).

Therefore, it is very important to study the relationship between soil microbial diversity and plants to understand the occurrence and development of crop root rot. Plants depend on the ability of roots to communicate with rhizosphere soil microorganisms through signaling pathways, creating a connection between plants and microorganisms (Meena et al., 2013; Li et al., 2016; Kumar et al., 2017). The composition of the rhizosphere soil microbiota can negatively or positively influence plant traits such as stress tolerance, health, development, and productivity (Kristin and Miranda, 2013; Lakshmanan et al., 2014; Miao et al., 2016). The plant, 
88 in turn, cultivates the structural and functional diversity of microbial communities in the 89 rhizosphere soil by adjusting soil $\mathrm{pH}$, releasing secondary metabolites into the rhizosphere soil 90 (Chakraborty et al., 2011; Meena et al., 2016; Kumar et al., 2017), reducing competition for 91 beneficial microbes, and providing an energy source, mostly in the carbon-rich rhizosphere soil 92 (Davis et al., 2008; Rashida et al., 2016). Nutrients are also drivers for rhizosphere soil community structure. Soil-plant-microbial health must remain in equilibrium to maintain sustainable agricultural practices (Kumar et al., 2017; Narula et al., 2013; Ramirez-Bahena et al., 2013). Under unfavorable conditions, some fungi can cause plant diseases and sometimes even total loss of crop yields (Miao et al., 2016).

In addition to agrochemicals (Handiseni et al., 2013), fertilization (Phillips and Fahey, 2007; Ai et al., 2015), soil types (Buyer et al., 1999; Rasche et al., 2006), tillage (Lupwayi et al., 1998) and crop rotation (Kirkegard et al., 2008; Wintera et al., 2014), which can influence rhizosphere soil microorganisms, the structure and function of rhizosphere soil microbiota may also be affected by the plant physiology of different plant genotypes (Söderberg et al., 2002; Rasche et al., 2006) and may also fluctuate among the vegetation stages of the same plant genotype (Gyamfi et al., 2002; Rasche et al., 2006). Plant growth stage influences root physiology and changes the quality and quantity of root exudates; consequently, these changes select for different root-associated microorganisms at different growth stages (Dunfield and Germida, 2003; Houlden et al., 2008; Li et al., 2014). The purpose of this study was to study the diversity of fungi, the variation in community structure and the trends in the microbial species in the rhizosphere soil of healthy and diseased wheat roots at different heading and filling stages of wheat growth. Additionally, by combining these results with the physical and chemical properties of soil, the possible causes of wheat root rot disease were revealed, providing an important theoretical basis and practice for the improved control of wheat root rot disease.

\section{MATERIALS \& METHODS}

\section{Rhizosphere soil sampling}

Field experiments were approved by the Research Council of the Institute of Plant Protection and Soil \& Fertilizer, Hubei Academy of Agricultural Sciences (project number:17.035.18).

The Institute of Plant Protection and Soil \& Fertilizer, Hubei Academy of Agricultural Sciences granted Ethical approval to carry out the study within its facilities (Ethical Application 
Ref: hb375-a6c3d).

In Xiangyang Original Farm, from wheat filling stage in early April to dough stage in May, the physiological growth of wheat plants changed rapidly, and the root exudates changed sharply from April to May, which were important factors influencing the great changes of rhizosphere microorganisms. In addition, the rapid change of temperature is also an important factor. The temperature is around 17 degrees in early April and 24 degrees in early May.

From 2010 to 2016, we conducted the investigation and efficacy control test of wheat root rot disease in Xiangyang Original Farm for six consecutive years. According to our investigation and experiment, we found that the root rot of wheat plantation in Xiangyang Original Farm occurred seriously (the disease index reaches $43 \%$ Fig. 1A), and the main pathogenic factors were continuous cropping obstacle, large temperature variation, rice and wheat crop rotation. The main root rot occurred in the wheat field of Xiangyang Original Farm was caused mainly by Gaeumannomyce gramim (Sacc.) Arx et Olivier, Pellicularia Rolfsii (Sacc.) West, Rhizoctonia cerealis and F. oxysporum F.S.P. Niveum.

The symptoms of wheat root rot in April were not particularly obvious, so multiple rhizosphere soil samples were collected from multiple points. Then, we defined and selected rhizosphere soil samples collected in April by the sample area with the most significant symptoms of wheat root rot in May (Fig. 1B). The sampling method consisted of first investigating the occurrence of wheat root rot, selecting weak seedlings and sampling the brown parts of the root as the diseased wheat rhizosphere. Areas with diseased wheat and healthy wheat (the diameter of each area was not more than $10 \mathrm{~m}$ ) were marked by inserting cards at fixed points at least 10 meters apart. Five samples were collected from the healthy and diseased rhizosphere soil respectively in May, then we selected five samples from the corresponding healthy and diseased wheat area respectively in April.

The roots of the whole plant and the soil on the roots were collected. The majority of soil on the roots was shaken off, and samples were collected for the determination of physical and chemical soil properties. The rhizosphere soil samples wheat plants were placed in a sealed pocket and quickly stored in a dry-ice box for dry-ice preservation. After all the samples were collected, they were immediately brought to the laboratory and stored in a cryogenic refrigerator for future use.

\section{Extraction and PCR amplification of total genomic DNA from rhizosphere soil fungi}


149 The soil attached to the root was brushed off, a 0.1-g soil sample was accurately weighed, and

150 the total genomic DNA from all samples was extracted according to the instructions provided 151 with an E.Z.N.A.® soil DNA Kit (Omega Biotek, Norcross, GA, U.S.). Total DNA was detected 152 by $1 \%$ agarose gel electrophoresis, and the purity and concentration of DNA were determined 153 with NanoDrop 2000 UV-vis spectrophotometer (Thermo Scientific, Wilmington, USA). All 154 DNA samples were stored in a refrigerator at $-20{ }^{\circ} \mathrm{C}$. Fungal diversity was determined by amplifying the ITS1 region using the ITS1F and ITS2R primer sets for fungi. The primer 156 sequences were ITS1F 5'- CTTGGTCATTTAGAGGAAGTAA-3' and ITS2R 5'-

157

158

GCTGCGTTCTTCATCGATGC-3', and the amplification conditions were predenaturation at $95^{\circ} \mathrm{C}$ for $5 \mathrm{~min}, 27$ cycles of $95^{\circ} \mathrm{C}$ for $30 \mathrm{~s}, 55^{\circ} \mathrm{C}$ for $30 \mathrm{~s}$, and $72^{\circ} \mathrm{C}$ for $45 \mathrm{~s}$, and elongation at $72^{\circ} \mathrm{C}$ for $5 \mathrm{~min}$. Three replicates of the PCR were performed, and a $20-\mu \mathrm{L}$ reaction system $(4 \mu \mathrm{L}$ of $5 \times$ FastPfu buffer solution, $2 \mu \mathrm{L}$ of $2.5 \mathrm{mM}$ dNTPs, $0.8 \mu \mathrm{L}$ of primer $(5 \mu \mathrm{M}), 0.4 \mu \mathrm{L}$ of FastPfu polymerase and $10 \mathrm{ng}$ of fungal total genomic DNA) was used.

\section{Illumina HiSeq2500 sequencing}

Purified amplicons were pooled in equimolar and paired-end sequenced on an Illumina MiSeq PE300 platform/NovaSeq PE250 platform (Illumina, San Diego,USA) according to the standard protocols by Majorbio Bio-Pharm Technology Co. Ltd. (Shanghai, China). The raw reads were deposited into the NCBI Sequence Read Archive (SRA) database (Accession Number: PRJNA549031).

\section{Data processing}

The sequencing depth was more than 30,000 original reads per library. Raw fastq files were demultiplexed, quality-filtered by Trimmomatic (Bolger et al., 2014) and merged by FLASH 1.2.7 (Magoč et al., 2011) with the following criteria: (i) The 300bp reads were truncated at any site receiving an average quality score of $<20$ over a 50 bp sliding window, and the truncated reads shorter than $50 \mathrm{bp}$ were discard, reads containing ambiguous characters were also discarded; (ii) only overlapping sequences longer than $10 \mathrm{bp}$ were assembled according to their overlapped sequence. The maximum mismatch ratio of overlap region is 0.2 . Reads that could not be assembled were discarded; (iii) Samples were distinguished according to the barcode and 
177 primers, and the sequence direction was adjusted, exact barcode matching, 2 nucleotide 178 mismatch in primer matching.

\section{OTU and species community analysis}

180 Operational taxonomic units (OTUs) with 97\% similarity cutoff were clustered using UPARSE

181

182

183 version 7.1 (Edgar, 2013; Stackebrandt and Goebel, 1994). and chimeric sequences were identified and removed using UCHIME. The taxonomy of each OTU representative sequence was analyzed by RDP Classifier version 2.2 (Wang et al., 2007) against the Unite (Release 7.0 http://unite.ut.ee/index.php) database using confidence threshold of $70 \%$. Finally, the effective tag data, low-frequency tag data, annotated tag data, and OTU data obtained from each sample were counted by a script. Additionally, we used R software to calculate the annotation ratio of OTUs and each taxonomic level and the relative abundance of the species in each taxonomic level.

Based on the above valid OTU data, the following evolutionary analysis was carried out: a) evolutionary relationships and relative abundance information of species systems based on OTU data in samples were determined, and species annotation results for a single sample were visualized using KRONA software (http://sourceforge.net/projects/krona); b) related genera were selected, a phylogenetic tree for the OTUs of these genera was constructed (QIIME software package: make_phylogeny.py (http://qiime.org/scripts/make_phylogeny.html)), and the systematic evolutionary relationship was displayed by combining the relative abundance of OTUs and the reliability of annotation using a Perl script; and c) local Perl scripts were used to select the dedicated OTUs for intrasample and intersample phylogenetic analysis and to compare relative abundance.

To analyze the community structure of species, relative abundance thermograms were plotted at the OTU level and the genera level by R software. Alpha diversity was analyzed using mothur software. The data of soil physical and chemical properties was analyzed by SPSS 16.0 software. Cluster analysis and principal coordinate analysis (PCoA) were also carried out to compare samples.

\section{RESULTS}

\section{Fungal diversity in the rhizosphere soil of wheat root}

According to the diversity index, the community richness and diversity of the diseased groups 
207 were higher than those of the healthy groups in the heading stage, and there was a significant 208 difference in community diversity between the diseased group and the healthy group (Shannon 209 index: $P<0.01$ ) (Table 1). High community richness can also be a factor in disease suppression.

210 However, the community richness and diversity of the disease group and the healthy group in the 211 filling stage were higher than those of the disease group and the healthy group in the heading 212 stage, and there was a significant difference between the disease group and the healthy group in 213 the heading stage (Sobs index: $P<0.05$; Shannon index: $P<0.05$ ). The community richness and 214 diversity of the healthy group in the filling stage were higher than those of the diseased group in 215 the filling stage.

\section{Community structure of fungi in the rhizosphere soil}

217 There were 1393 OTUs distributed among six phyla, 346 genera and 549 species. The six phyla were Ascomycota, Basidiomycota, Zygomycota, Chytridiomycota, Glomeromycota, and Blastocladiomycota (Fig. 2A). Among these phyla, Ascomycota was the most abundant. The richness values were $65.48 \%$ and $67.61 \%$ in healthy groups 4 and 5 (H4 and H5, respectively), and $72.57 \%$ and $57.35 \%$ in diseased groups 4 and 5 (D4 and D5, respectively), respectively, but there was no significant difference among the populations. The other three phyla showed very interesting results. Basidiomycota had the highest abundance in population H4 in the heading stage (25.3\%). However, in the D4, D5 and H5 populations, the abundance was significantly decreased to $12.36 \%, 11.16 \%$ and $14.7 \%$, respectively. Significant differences were found between populations $\mathrm{H} 4$ and D4 and populations D5 and H5 $(\mathrm{P}<0.01)$. The abundance of Zygomycota in populations H4 and D4 was low in the heading stage $(3.16 \%$ and $2.44 \%$, respectively), but suddenly increased to $9.87 \%$ (H5) and $7.42 \%$ (D5) in the filling stage. However, the trends in the abundance of Chytridiomycota and Zygomycota were almost the opposite. The abundance of Chytridiomycota in the heading stage groups was $4.52 \%(\mathrm{H} 4)$ and $7.18 \%$ (D4), and there was a significant difference between these two groups. The abundance of Chytridiomycota in population D4, a diseased group, was much higher than that in the healthy groups. By May, the abundance of Chytridiomycota in population H5 decreased sharply to $1.37 \%$, while that of population D5 decreased to only $4.12 \%$.

Excluding unclassified fungi, all fungi with richness greater than $1 \%$ in a single group were counted (Table 2). There are 30 genera in the four groups belonging to Ascomycota, 
238 Zygomycota had only one genus, Olpidiaster and Portierella, respectively. Basidiomycota had 239 seven genera, and Ascomycota had the largest distribution, with 21 genera (Fig. 2B and C, Table 240 2). In the heading stage, the abundance of the most highly abundant genera in population D4 was 241 significantly decreased in population D5 at the filling stage; however, the abundance of 242 Mortierella significantly increased, the abundance of one-third of the genera remained almost 243 unchanged, and the abundance of a few low abundance genera, such as Fusarium and 244 Ceratobasidium, significantly increased in the diseased population over time. Seven genera with 245 high richness were found in the H4 population at the heading stage, and the richness of these 246 genera was significantly increased in the H5 population at the grain filling stage; among these 247 genera, the variation in the richness of Microdochium, Mycosphaerella, Scytalidium, 248 Acremonium and Olpidiaster from the $\mathrm{H} 4$ population to the H5 population was the opposite of 249 the change in abundance from the D4 population to the D5 population. The richness of 13 genera 250 did not markedly change, and the richness of 4 low-richness genera was significantly increased 251 at the grain filling stage compared with the heading stage. In general, the following six genera 252 showed no change in richness from the heading stage to the grain filling stage, between the H5 253 and D5 populations and the H4 and D4 populations, respectively, Alternaria, Sarocladium, 254 Gibberella, Cladosporium, Neosetophoma and Cystofilobasidium. The genera with significant or 255 extremely significant differences in richness among the groups were Alternaria, Mortierella, Cryptococcus, Apodus, Epicoccum, Scytalidium and Chaetomium.

A Venn diagram of genera with richness greater than 1\% was constructed (Fig. 2D). There were 153 shared genera, 35 endemic genera that appeared most frequently in the healthy group in the filling stage and 7 and 10 genera in the heading stage and filling stage, respectively. The results showed that the root exudates of diseased plants specifically promoted the growth of microbial fungi, while the rhizosphere of healthy plants was more suitable for the growth of various fungi. An increased diversity of soil microorganisms promoted healthy plant growth.

263

264

\section{PCoA of populations}

The PCoA of fungal community structure in different samples based on OTU revealed that the populations could be divided into two groups: the healthy group and the diseased group (Fig. 3A and B). There was no overlap between the two groups, which indicated that the samples were consistent with the expectation and that the microbial community structures of the diseased group and the healthy group were quite different. The diseased group at the heading stage was 
269 significantly separated from the diseased group at the filling stage, and the microbial community

270 structure was quite different. The healthy group at the heading stage and the healthy group at the

271 filling stage were also clearly separated, and the microbial community structure was quite

272 different. In addition, according to the flora classification, all rhizosphere fungi were divided into

273 two types (Fig. 3C): type one included the diseased group, and type two included the healthy

274 group. Only sample H5-5 was assigned to type one.

\section{Effects of physical and chemical soil properties on rhizosphere fungi}

276 The main physical and chemical properties of soil measured were total phosphorus (TP), 277 ammonium nitrogen $\left(\mathrm{NH}_{4}\right)$, nitrate nitrogen $\left(\mathrm{NO}_{3}\right)$, total nitrogen $(\mathrm{TN}), \mathrm{pH}$, soil density (SD), 278 total carbon (TC) and the soil dry-humidity ratio (DHR) (Table 3). TP and TC decreased and $279 \mathrm{NH}_{4}$ increased from the heading stage to the filling stage. Moreover, the $\mathrm{NO}_{3}$ and $\mathrm{TN}$ of the 280 diseased group were higher than those of the healthy group, and the $\mathrm{pH}$ value and SD of the 281 diseased group were lower than those of the healthy group. Heatmap cluster analysis based on 282 Spearman correlation coefficients for the 30 genera with the most richness and these physical

283

284

285

286

287

288

289

290

291

292

293

294

295

296

297

298 and chemical indicators was performed (Fig. 4). The graph shows that $\mathrm{pH}$ and SD have the greatest influence on microbial abundance, and the influence of these factors is in the same direction. Soil density refers to the dry weight of unit volume soil (g/cm3) (not including soil pore), which also represents water saturation. Soil density can affect the soil microbial diversity and community structure. One-third of the genera were positively or significantly positively correlated with both $\mathrm{pH}$ and $\mathrm{SD}$, and one-third were negatively or significantly negatively correlated with both $\mathrm{pH}$ and $\mathrm{SD}$. The effects of $\mathrm{NO}_{3}$ and $\mathrm{TN}$ on microbial richness were similar, but the impact of these factors on microbial species richness was almost the opposite of that of $\mathrm{pH}$ and SD. From our results, there is relationship between them, but from previous similar research, there is no necessary reverse relationship between them. Soil DHR and TP had moderate effects on microbial richness. The physical and chemical properties of soil with the least influence on microbial abundance were $\mathrm{NH}_{4}$ and TC.

\section{DISCUSSION}

Microbial diversity in soil is an important factor that determines soil health and is considered one of the main contributors to soil suppressiveness (Xu et al., 2012; Miao et al., 2016). The rhizosphere is one of the most complex environments; rhizospheres are influenced by plant roots 
299

300

301

302

303

304

305

306

307

308

309

310

311

312

313

314

315

316

317

318

319

320

321

322

323

324

325

326

327

328

329

and are an active microhabitat where plant roots and microbes interact (Xu et al., 2012; Mendes et al., 2013; Singh et al., 2014). Throughout the heading and filling stages of wheat, the fungi in the rhizosphere soil showed high diversity. The diversity of soil fungi at the grain filling stage was significantly higher than that at the heading stage. It is already well known that most crops can significantly benefit from establishing associations with diverse soil microbes (Kristin and Miranda, 2013). Plants stimulate or inhibit the growth of specific rhizosphere microorganisms by releasing secondary metabolites into the rhizosphere (Chakraborty et al., 2011; Meena et al., 2016; Kumar et al., 2017). For example, Flavonoids can resist root bacteria (there are many studies on fungi) and play a bactericidal effect in the way of cell death: compounds are oxidized to release toxic active ions leading to cell death; Degradation of ATPASE and mitochondrial respiratory electron transporter on the membrane to achieve cell death (Zhalnina et al., 2018). In the rhizosphere soil of wheat root rot disease, the interaction between wheat and microorganisms was intense, and the diversity and richness of the fungal community in the rhizosphere soil of the diseased group were significantly higher than that of the healthy group, creating conditions for the occurrence of wheat root rot. However, at the filling stage, wheat roots were clearly diseased due to infection by pathogenic fungi. During this process, the metabolites secreted by wheat roots tend to be less (Chen et al., 2019). As a result, the fungi in the rhizosphere of diseased plants showed lower community diversity and richness than those in the rhizosphere of healthy plants. The interaction between rhizosphere fungi and wheat roots in the healthy group reached an optimal balance during the filling stage and then became mutualistic, which was favorable for the healthy growth of the fungi and wheat. Therefore, in the filling stage, the diversity and richness of fungi in the rhizosphere were higher in the healthy group than in the diseased group.

The richness change analysis at the phylum level revealed that the phylum with the highest richness was Ascomycota, which consisted of more than $60 \%$ of all healthy and diseased groups, and there was no significant difference among groups. However, the main pathogenic fungi that cause wheat root rot disease, such as F. culmorum, F. pseudograminearum, G. graminis var. Tritici, B. sorokiniana and Alternaria spp., are in this phylum. There are also some fungi that cause wheat root rot in the phylum Basidiomycota, such as Rhizoctonia oryzae, R. solani and Penicillium spp (Almasudy et al., 2015; Barnett et al., 2019; Gqozo et al., 2020; Zhang et al., 2021). This phylum showed high richness in the healthy group at the heading stage (25.3\%), but the richness of this phylum was significantly decreased in the other groups $(<14 \%)$. Analysis of 
330 the abundance of these two phyla shows that the impact of the fungi that cause wheat root rot

331 disease is not due to phylum-level abundance. The richness of two other phyla, Zygomycota and

332 Chytridiomycota, which contain almost no root rot fungi, showed notable differences between

333 the heading and filling stages in the healthy group but showed no significant differences between

334 these stages in the diseased groups. This change in abundance may contribute to the healthy

335 growth of wheat roots or may be a cofactor in the occurrence of wheat root rot disease.

336 Relative to the changes at the phylum level, levels of richness at the genera level varied

337 greatly. The abundance of most genera with high richness decreased significantly from the

338 heading stage to the filling stage in the diseased groups; the richness of approximately one-third

339 of all genera remained unchanged, and only very few low-richness genera, such as Fusarium and

340 Ceratobasidium, had a very significant increase in richness over time. In the healthy group, the

341 abundance of most genera increased significantly from the heading stage to the filling stage,

342 except for some genera whose abundance did not markedly change or very few genera whose

343 abundance increased significantly. This result also shows that the interactions between wheat

344 roots and rhizosphere fungi must achieve a balance. If this balance is lost, the wheat roots will

345 become diseased. From the analysis of the endemic genera in each group, we also found that

346 there were 35 endemic genera in the healthy group, which was many more than the

347 approximately 10 endemic genera in the diseased group, indicating that the healthy growth of

348 wheat roots can promote plant growth and suppress disease through various activities that

349 prevent infection by pathogens. Therefore, the rhizosphere microorganisms show improved

350 growth, and the microbial diversity and community richness are also significantly increased in

351 the healthy plants compared with the diseased plants.

352 Fungi and fungus-like organisms form one of the most diverse groups of eukaryotes and 353 represent an essential functional component of soil microbial communities (Buée et al., 2009; 354 Miao et al., 2016). Under unfavorable conditions, some fungi can cause plant diseases and 355 sometimes even the total loss of crop yields. In many instances, these diseases are caused by a 356 complex of fungal species (Miao et al., 2016). Only Alternaria and Fusarium, genera with 357 richness values greater than one percent, have been documented to cause wheat root rot, but the 358 abundance of these two genera is not high. Although the abundance of Alternaria in the diseased 359 groups was significantly higher than that in the healthy groups, there was no significant change 360 between the heading stage and filling stage. The abundance of Fusarium in the filling stage was 
361 significantly higher than that in the heading stage. Considering the abundance of these two 362 pathogens, the richness level of a fungus does not indicate whether it can lead to wheat root rot. 363 In addition, other pathogenic fungal genera mentioned in the literature were determined to have 364 less than one percent abundance. Therefore, we can speculate that as long as these fungal genera 365 exist in the rhizosphere, they can lead to wheat root rot disease, regardless of the abundance. 366 However, whether a fungus can induce root rot disease depends on the result of the interaction 367 between wheat root and rhizosphere microorganisms, which is also closely related to seasonal 368 climatic conditions (Campanella et al., 2020).

369 Differences in the fungal community structure among groups can clearly demonstrate the 370 heterogeneity of each group, thus showing why there are so many differences in the rhizosphere 371 fungi of the diseased groups and the healthy groups (Karuppiah et al., 2020). PCoA clustering analysis clearly clustered the four groups into two groups: the healthy group and the diseased group. However, the healthy group and the diseased group were each clearly separated into the heading stage and grouting stage. In addition, all rhizosphere fungi were divided into two types according to flora classification: one type included only the healthy group, and the other type included only the diseased group. When wheat roots were attacked by microorganisms and developed root disease, the structure of the rhizosphere fungal community was markedly changed (Stephen et al., 2019). To differentiate between the fungi located very close to the epidermis in the root zone and to protect against the invasion of heterogeneous microbes, plants continuously secrete signaling molecules, which allows for the development of pathogenic, associative, symbiotic, or naturalistic relationships between microbes and the plant (Kumar et al., 2017; Hayat et al., 2010).

At the heading stage, the root is slightly diseased, and the interaction between wheat roots and rhizosphere fungi is the most intense, resulting in marked heterogeneity of the soil environment and inducing a high level of rhizosphere fungal diversity and a complex community structure. However, at the filling stage, the wheat roots are completely diseased. At this time, the soil environment is stable, and the material secreted by wheat roots is relatively limited, which leads to a decrease in the microbial diversity of the rhizosphere and a relatively simple community structure. Soil-plant-microbial health must be maintained at an equilibrium to maintain sustainable agricultural practices (Narula et al., 2013; Ramırez-Bahena et al., 2013; Kumar et al., 
392 rhizosphere fungi reaches a balance and promotes the healthy growth of wheat and fungi. By the 393 filling stage, the ecological environment, such as temperature, humidity and other factors, is

394

395

396

397

398

399

400

401

402

403

404

405

406

407

408

409

410

411

412

413

414

415

416

417

418

419

420

421

422

improved, the rhizosphere microbial diversity naturally significantly increases, and the community structure becomes more complex. When microbial diversity increases, the beneficial microorganisms will also increase, which will improve the inhibitory effect of plant roots, thus reducing the occurrence of plant root rot (Hu et al., 2016).

Biotic and abiotic factors are assumed to influence the structural and functional diversity of the microbial communities in the rhizosphere (Berg and Smalla, 2009; Weinert et al., 2011). Site properties, including soil type, climatic conditions and type of agricultural management, have been shown to strongly influence the relative composition of rhizosphere microbial communities (Hener et al., 2002; Kowalchuk et al., 2002; Berg et al., 2006; Costa et al. 2006; Bremer et al., 2007; Weinert et al., 2010). Changes in the physical and chemical properties of soil also have a significant impact on fungal diversity and community structure in crop rhizospheres. Soil physical and chemical properties are determined not only by the nature of the soil itself but also by the physical and chemical properties of the soil after the interaction between crop roots and rhizosphere fungi. The physical and chemical soil properties we measured were determined in soil collected around the rhizosphere of wheat (Zhang et al., 2017). Organisms that are present in the rhizosphere microbiota can have profound effects on the growth, nutrition and health of plants in agroecosystems (Bonfante and Anca, 2009; Mendes et al., 2011; Meena et al., 2015; Kumar et al., 2017). TP and TC decreased from the heading stage to the filling stage, indicating that the later the growth period was, the less TP and TC was needed; however, these metrics seemed unrelated to the occurrence of diseases. In addition, the levels of $\mathrm{NH}_{4}, \mathrm{NO}_{3}$ and $\mathrm{TN}$ in the diseased group were higher than those in the healthy group at the heading and filling stages, indicating that their increase contributed to the occurrence of wheat root rot disease. Too much ammonium nitrogen and total nitrogen can easily damage the root system of the plant, then it can easily attract pathogenic fungi to attack the damaged root system of the plant, resulting in the occurrence of root to disease (Zhang et al., 2021). In contrast, the $\mathrm{pH}$ and SD of the soils around diseased plants were lower than those of the soils around healthy plants at the heading and filling stages. This finding indicated that relatively low $\mathrm{pH}$ and $\mathrm{SD}$ values were beneficial to the occurrence of wheat root rot disease. The heatmap cluster analysis of the physical and chemical soil indicators and the 30 most abundant genera also showed that soil $\mathrm{pH}$ and SD affected fungal

PeerJ reviewing PDF | (2021:07:64098:1:1:NEW 29 Oct 2021) 
423 abundance and diversity in the same direction.

424

425

426

427

428

429

430

431

432

433

434

435

436

437

438

439

440

441

442

443

444

445

446

447

448

449

450

451

\section{CONCLUSIONS}

In the rhizosphere, many plant-microbial interactions occur that mediate soil processes (Kumar et al., 2017). The occurrence of crop root rot disease is closely related to the interaction between rhizosphere microorganisms and crop roots, as well as the physical and chemical properties of soil. At present, there are approximately 10 types of fungi that can cause wheat root rot disease alone or in a complex, according to the literature. By studying the diversity of fungi and the community structure of the rhizospheres of healthy and diseased wheat at different growth stages, the heading and filling stages, it was revealed that in the early stages of illness, the high diversity of rhizosphere fungi and a complex community structure can easily cause wheat root rot disease. Additionally, the existence of pathogenic fungi is a necessary condition for wheat root rot disease, but the richness of pathogenic fungi is not necessarily important. Based on the physical and chemical properties of the soil, an increase in $\mathrm{NH}_{4}, \mathrm{NO}_{3}$ and $\mathrm{TN}$ contributes to the occurrence of wheat root rot disease. Soil $\mathrm{pH}$ and SD had the greatest influence on the abundance and diversity of rhizosphere fungi, and the influence was in the same direction; low soil $\mathrm{pH}$ and SD are beneficial to the occurrence of wheat root rot disease.

\section{ADDITIONAL INFORMATION AND DECLARATIONS}

\section{Funding}

This work was financially supported by the National Key Research and Development Program of China (2017YFD0200605), the Key Research and Development Project (2017YFD0201600), and Key Technology Research and Demonstration Project of Hubei Agricultural Science and Technology Innovation Center (2020-620-000-002-07).

\section{Grant Disclosures}

The following grant information was disclosed bye the authors:

The National Key Research and Development Program of China: No. 2017YFD0200605.

The Key Research and Development Project: No. 2017YFD0201600.

Key Technology Research and Demonstration Project of Hubei Agricultural Science and Technology Innovation Center (2020-620-000-002-07).

\section{Declaration of competing interest}


452 The authors declare there are no competing interests.

\section{Author Contributions}

454 -Xuejiang Zhang and Hua Wang conceived and designed the experiments, performed the 455 experiments, analyzed the data, prepared figures and/or tables, authored or reviewed drafts of the 456 paper, and approved the final draft.

457 - Heyun Wang and Yawei Que analyzed the data, prepared figures, and approved the final draft.

458 - Gavin Ash and Dazhao Yu conceived and designed the experiments, authored or reviewed 459 drafts of the paper, and approved the final draft.

460 Ethics

461 The following information was supplied relating to ethical approvals (i.e., approving body and any reference numbers):

463 The Institute of Plant Protection and Soil \& Fertilizer, Hubei Academy of Agricultural 464 Sciences granted Ethical approval to carry out the study within its facilities (Ethical Application 465 Ref: hb375-a6c3d).

\section{Field Study Permissions}

467 The following information was supplied relating to field study approvals (i.e., approving body 468 and any reference numbers):

469 Field experiments were approved by the Research Council of the Institute of Plant Protection 470 and Soil \& Fertilizer, Hubei Academy of Agricultural Sciences (project number:17.035.18).

\section{Data Availability}

472 The following information was supplied regarding data availability:

473 The data are available at NCBI: PRJNA549031.

\section{REFERENCES}

Ai C, Liang GQ, Sun JW, Wang XB, He P, Zhou W, He XH. 2015. Reduced dependence of rhizosphere microbiome on plant-derived carbon in 32-year long-term inorganic and organic fertilized soils. Soil Biology \& Biochemistry 80:70-78 DOI 10.1016/j.soilbio.2014.09.028.

Almasudy AM, You MP, Barbetti MJ. 2015. Influence of fungicidal seed treatments and soil type on severity of root disease caused by rhizoctonia solani ag- 8 on wheat. 
Crop Protection 75: 40-45 DOI 10.1016/j.cropro.2015.05.007.

Almasudy AM, You MP, Barbetti MJ. 2015. Influence of fungicidal seed treatments and soil type on severity of root disease caused by Rhizoctonia solani AG-8 on wheat. Crop Protection 75:40-45 DOI 10.1016/j.cropro.2015.05.007.

Assaf TA, Turk MA, Ameed KM. 2009. Impact of olive pomace wastes and fungicide treatment on indigenous arbuscular mycorrhizal fungi associated with chickpea (Cicerarietinum L.) under field conditions. Austtralian Journal of Crop Science 3:6-12 DOI 10.2134/agronj2008.0158N.

Barnett SJ, Ballard RA, Franco C. 2019. Field assessment of microbial inoculants to control rhizoctonia root rot on wheat. Biological Control 132:152-160 DOI 10.1016/j.biocontrol.2019.02.019.

Berg G, Opelt K, Zachow C, Lottmann J, GÖtz M, Costa R, Smalla K. 2006. The rhizosphere effect on bacteria antagonistic towards the pathogenic fungus Verticillium differs depending on plant species and site. FEMS Microbiology Ecology 56:250-261 DOI 10.1111/j.1574-6941.2005.00025.x.

Berg G, Smalla K. 2009. Plant species and soil type cooperatively shape the structure and function of microbial communities in the rhizosphere. FEMS Microbiology Ecology 68:1-13. DOI 10.1111/j.1574-6941.2009.00654.x.

Bolger AM, Lohse M, Usadel B. 2014. Trimmomatic: a flexible trimmer for Illumina sequ ence data. Bioinformatics 30(15): 2114-2120 DOI 10.1093/bioinformatics/btu170.

Bonfante P, Anca IA. 2009. Plants, mycorrhizal fungi, and bacteria: a network of interactions. Annual Review of Microbiology 63:363-383 DOI 10.1146/annurev.micro.091208.073504.

Bremer C, Braker G, Matthies D, Reuter A, Engels C, Conrad R. 2007. Impact of plant functional group, plant species, and sampling time on the composition of nirK-type denitrifier communities in soil. Applied Environmental Microbiology 73:6876-6884 DOI 10.1128/AEM.01536-07.

Buée M, Reich M, Murat C, Morin E, Nilsson RH, Uroz S, Martin F. 2009. 454 Pyrosequencing analyses of forest soils reveal an unexpectedly high fungal diversity. New Phytologist 184:449-456 DOI 10.1111/j.1469-8137.2009.03003.x.

Buyer JS, Roberts DP, Russek-Cohen E. 1999. Microbial community structure and 
512

513

514

515

516

517

518

519

520

521

522

523

524

525

526

527

528

529

530

531

532

533

534

535

536

537

538

539

540

541

542

function in the spermosphere as affected by soil and seed type. Canadian Journal of Microbiology 45:138-144 DOI 10.1139/cjm-45-2-138.

Campanella V, Mandalà C, Angileri V, Miceli C. 2020. Management of common root rot and Fusarium foot rot of wheat using Brassica carinata break crop green manure. Crop Protection 130:105073 DOI 10.1016/j.cropro.2019.105073.

Chakraborty U, Swarnendu R, Pratim CA, Pannalal D, Bishwanath C. 2011. Plant growth promotion and amelioration of salinity stress in crop plants by a salt-tolerant bacterium. Recent Research in Science \& Technology 3:61-70.

Chen S, Waghmode TR, Sun R. 2019. Root-associated microbiomes of wheat under the combined effect of plant development and nitrogen fertilization. Microbiome DOI 10.1186/s40168-019-0750-2.

Costa R, Götz M, Mrotzek N, Lottmann J, Berg G, Smalla K. 2006. Effects of site and plant species on rhizosphere community structure as revealed by molecular analysis of microbial guilds. FEMS Microbiology Ecology 56:236-249 DOI 10.1111/j.15746941.2005.00026.x.

Davis RA, Huggins D, Cook RJ, Paulitz TC. 2008. Can placement of seed away from relic stubble limit Rhizoctonia root rot in direct-seeded wheat? Soil \& Tillage Research 101:37-43 DOI 10.1016/j.still.2008.05.014.

Duffy B. 2000. Combination of Pencycuron and Pseudomonas yuorescens strain 2-79 for integrated control of Rhizoctonia root rot and take-all of spring wheat. Crop Protection 19:21-25 DOI 10.1016/S0261-2194(99)00078-2.

Dunfield KE, Germida JJ. 2003. Seasonal changes in the rhizosphere microbial communities associated with field-grown genetically modified canola (Brassica napus). Applied and Environmental Microbiology 69:7310-7318 DOI 10.1128/aem.69.12.7310-7318.2003.

Gqozo MP, Bill, M., Siyoum N, Labuschagne N, Korsten L. 2020. Fungal diversity and community composition of wheat rhizosphere and non-rhizosphere soils from three different agricultural production regions of south africa. Applied Soil Ecology 151 DOI 10.1016/j.apsoil.2020.103543.

Gyamfi S, Pfeifer U, Stierschneider M, Sessitsch A. 2002. Effects of transgenic glufosinate-tolerant oilseed rape (Brassica napus) and the associated herbicide 
application on eubacterial and pseudomonas communities in the rhizosphere. FEMS Microbiology Ecology 41:181-190 DOI 10.1016/S0168-6496(02)00290-8.

Edgar RC. 2013. UPARSE: highly accurate OTU sequences from microbial amplicon reads. Nature Methods 10(10): 996-998. DOI 10.1038/nmeth.2604.

Handiseni M, Brow J, Zemetra R, Mazzol M. 2013. Effect of Brassicaceae seed meals with different glucosinolate profiles on Rhizoctonia root rot in wheat. Crop Protection 48:1-55 DOI 10.1016/j.cropro.2013.01.006.

Hayat R, Ali S, Amara U, Khalid R, Ahmed I. 2010. Soil beneficial bacteria and their role in plant growth promotion: a review. Annals of Microbiology 60:579-598 DOI 10.1007/s13213-010-0117-1.

Heuer H, Kroppenstedt RM, Lottmann J, Berg G, Smalla K. 2002. Effects of T4 lysozyme release from transgenic potato roots on bacterial rhizosphere communities are negligible relative to natural factors. Applied Environmental Microbiology 68:1325-1335 DOI 10.1128/AEM.68.3.1325-1335.2002.

Houlden A, Timms-Wilson TM, Day MJ, Bailey MJ. 2008. Influence of plant developmental stage on microbial community structure and activity in the rhizosphere of three field crops. FEMS Microbiology Ecology 65:193-201 DOI 10.1111/j.15746941.2008.00535.x.

Hu J, Wei Z, Friman VP, Gu SH, Wang XF, Eisenhauer N, Yang TJ, Ma J, Shen QR, Xu YC, Jousset A. 2016. Probiotic Diversity Enhances Rhizosphere Microbiome Function and Plant Disease Suppression. mBio. 7(6): e01790-16 DOI 10.1128/mBio.01790-16.

Karuppiah V, Li YQ, Sun JN, Vallikkannu M, Chen J. 2020. Vel1 regulates the growth of Trichoderma atroviride during co-cultivation wiht Bacillus amyloliquefaciens and is essential for wheat root rot control. Biological Control 151:104374 DOI 10.1016/j.biocontrol.2020.104374.

Kirkegard J, Christen O, Krupinsky J, Layzell D. 2008. Break crop benefits in temperate wheat production. Field Crops Research 107:185-195 DOI 10.1016/j.fcr.2008.02.010.

Kowalchuk GA, Buma DS, de Boer W, Klinkhamer PGL, van Veen JA. 2002. Effects of above-ground plant species composition and diversity on the diversity of soil-borne 
microorganisms.

Antonie

van

Leeuwenhoek

81:509-520.

DOI

575

576 10.1023/a:1020565523615.

Kristin A, Miranda H. 2013. The root microbiota—a fingerprint in the soil? Plant Soil 370:671-686 DOI 10.1007/s 11104-013-1647-7.

Kumar A, Maurya BR, Raghuwanshi R, Meena VS, Islam MT. 2017. Co-inoculation with Enterobacter and Rhizobacteria on yield and nutrient uptake by wheat (Triticum aestivum L.) in the alluvial soil under the Indo-Gangetic Plain of India. Journal of Plant Growth Regulation 36:608-617 DOI 10.1007/s00344-016-9663-5.

Kumar A, PratushA. 2014. Molecular diversity and functional variability of environmental isolates of Bacillus species. SpringerPlus 3:2-11 DOI 10.1186/21931801-3-312.

Lakshmanan V, Selvaraj G, Bais HP. 2014. Functional soil microbiome: below ground solutions to an aboveground problem. Plant Physiology 166:689-700 DOI 10.1104/pp.114.245811.

Li M, Ahammed GJ, Li C, Bao X, Yu J, Huang C, Yin H, Zhou J. 2016. Brassinosteroid ameliorates zinc oxide nanoparticles-induced oxidative stress by improving antioxidant potential and redox homeostasis in tomato seedling, Front. Plant Science 7:615. DOI 10.3389/fpls.2016.00615.

Li XZ, Rui JP, Mao YJ, Yannarell A, Mackie R. 2014. Dynamics of the bacterial community structure in the rhizosphere of a maize cultivar. Soil Biolology \& Biochemistry 68:392-401 DOI 10.1016/j.soilbio.2013.10.017.

Lupwayi NZ, Rice WA, Clayton GW. 1998. Soil microbial diversity and community structure under wheat as influenced by tillage and crop rotation. Soil Biolology \& Biochemistry 30:1733-1741 DOI 10.1016/S0038-0717(98)00025-X.

Magoč T, Salzberg SL. 2011. FLASH: Fast length adjustment of short reads to improve genome assemblies. Bioinformatics 27: 2957-2963 DOI 10.1093/bioinformatics/btr507.

Mavrodi OV, Walter N, Elateek S, Taylor CG, Ubara PAO. 2012. Suppression of Rhizoctonia and Pythium root rot of wheat by new strains of Pseudomonas. Biological Control 62:93-102 DOI 10.1016/j.biocontrol.2012.03.013.

Meena RS, Meena VS, Meena SK, Verma JP. 2015. The needs of healthy soils for a healthy world. Journal of Cleaner Production 102:560-561. DOI 
Meena SK, Rakshit A, Meena VS. 2016. Effect of seed bio-priming and N doses under varied soil type on nitrogen use efficiency (NUE) of wheat (Triticumaestivum L.) under greenhouse conditions. Biocatalysis \& Agricultural Biotechnology 6:68-75 DOI 10.1016/j.bcab.2016.02.010.

Meena VS, Maurya BR, Bohra JS, Verma R, Meena MD. 2013. Effect of concentrate manure and nutrient levels on enzymatic activities and microbial population under submerged rice in alluvium soil of Varanasi. Crop Research 45:6-12.

Mendes R, Garbeva P, Raaijmakers JM. 2013. The rhizosphere microbiome: significance of plant beneficial, plant pathogenic, and human pathogenic microorganisms. FEMS Microbiology Reviews 37:634-663 DOI 10.1111/1574-6976.12028.

Mendes R, Kruijt M, De Bruijn I, Dekkers E, van der Voort M, Schneider JHM, Piceno YM, DeSantis TZ, Andersen GL, Bakker PAHM, Raaijmakers JM. 2011. Deciphering the rhizosphere microbiome for disease-suppressive bacteria. Science 332:1097-1100 DOI 10.1126/science.1203980.

Miao CP, Mi QL, Qiao XG, Zheng YK, Chen YW, Xu LH, Guan HL, Zhao LX. 2016. Rhizospheric fungi of Panax notoginseng: diversity and antagonism to host phytopathogens. Journal of Ginseng Research 40:127-134 DOI 10.1016/j.jgr.2015.06.004.

Mielke H. 1998. Studien zum Befall des Weizens mit Gaeumannomyces graminis (Sacc.) von Arx et Olivier var. tritici Walker unter Berücksichtigung der Sortenund Artenanfäligkeit sowie der Bekäpfung des Erregers. Mitteilungen aus der Biologischen Bundesanstalt für Land-und Forstwirtschaft, Berlin-Dahlem. Heft pp. 359.

Narula S, Anand RC, Dudeja SS. 2013. Beneficial traits of endophytic bacteria from field pea nodules and plant growth promotion of field pea. Journal of Food Legumes 26:7379.

Okubara PA, Dickman MB, Blechl AE. 2014. Molecular and genetic aspects of controlling the soilborne necrotrophic pathogens Rhizoctonia and Pythium. Plant Science 228:61-70 DOI 10.1016/j.plantsci.2014.02.001.

Parkinson D, Coleman DC. 1981. Microbial communities, activity and biomass. Agriculture Ecosystems \& Environment 34:3-33 DOI 10.1016/0167-8809(91)90090-K. 
636

637

638
Paulitz TC, Adams K. 2003. Composition and distribution of Pythium communities in wheat fields in eastern Washington state. Phytopathology 93:867-873 DOI 10.1094/PHYTO.2003.93.7.867.

Paulitz TC, Scott RB. 2006. Effect of seed treatments for control of Rhizoctonia root rot in spring wheat. 2005. Fungicide and Nematicide Tests 61:ST014.

Paulitz TC, Smiley RW, Cook RJ. 2002. Insights into the prevalence and management of soilborne cereal pathogens under direct seeding in the Pacific Northwest, USA. Canadian Journal of Plant Pathology 24:416-428 DOI 10.1080/07060660209507029.

Phillips R, Fahey T. 2007. Fertilization effects on fine root biomass, rhizosphere microbes and respiratory fluxes in hardwood forest soils. New Phytologist 176:655-664 DOI 10.1111/j.1469-8137.2007.02204.x.

Ramırez-Bahena MH, Tejedor C, Martín I, Velaíquez E, Peix A. 2013. Enterobacter medicaginis gen. nov. sp. nov., isolated from alfalfa nodules in anacidic soil. International Journal of Systtematic and Evolutionary Microbiology 63:1760-1765 DOI 10.1099/ijs.0.041368-0.

Rasche F, Hödl V, Poll C, Kandeler E, Gerzabek MH, van Elsas JD, Sessitsch A. 2006. Rhizosphere bacteria affected by transgenic potatoes with antibacterial activities compared with the effects soil, wild-type potatoes, vegetation stage and pathogen exposure. FEMS Microbiology Ecology 56:219-235 DOI 10.1111/j.15746941.2005.00027.x.

Rashida MI, Mujawara LH, Shahzade T, Almeelbi TI, Iqbal MI, Oves M. 2016. Bacteria and fungi can contribute to nutrients bioavailability and aggregate formation in degraded soils. Microbiological Research 183:26-41 DOI 10.1016/j.micres.2015.11.007.

Schreiner RP, Bethlenfalvay GJ. 1996. Mycorrhizae, biocides, and biocontrol. 4. Response of a mixed culture of arbuscular mycorrhizal fungi and host plant to three fungicides. Biology and Ferttility of Soils 23:189-195 DOI 10.1046/j.1365294X.2002.01647.x.

Singh AK, Singh M, Dubey SK. 2014. Rhizospheric fungal community structure of a Bt brinjal and a near isogenic variety. The Journal of Applied Microbiology 117:750-765 DOI 10.1111/jam.12549. 
Sivasithamparam K. 1993. Ecology of root-infecting pathogenic fungi in Mediterranean environments. Advances in Plant Pathology 10:245-280.

Smith JD, Kidwell K, Evans M, Cook R, Smiley RW. 2003. Assessment of spring wheat genotypes for disease reaction to Rhizoctonia solani AG-8 in controlled environment and direct-seeded field evaluations. Crop Science 43:694-700 DOI 10.2135/cropsci2003.6940.

Söderberg KH, Olsson PA, Bååth E. 2002. Structure and activity of the bacterial community in the rhizosphere of different plant species and the effect of arbuscular mycorrhizal colonisation. FEMS Microbiology Ecology 40:223-231 DOI 10.1016/S0168-6496(02)00233-7.

Stackebrandt E, Goebel BM. 1994. Taxonomic Note: A Place for DNA-DNA Reassociation and 16S rRNA Sequence Analysis in the Present Species Definition in Bacteriology[J]. International Journal of Systematic Bacteriology 44(4): 846-849. DOI 10.1099/00207713-44-4-846.

Stephen JB, Ross AB, Christopher MMF. 2019. Field assessment of microbial inoculants to control Rhizoctonia root rot on wheat. Biological Control 132:152-160 DOI 10.1016/j.biocontrol.2019.02.019.

Taheri AE, Hamel C, Gan YT. 2015. Pyrosequencing reveals the impact of foliar fungicide application to chickpea on root fungal communities of durum wheat in subsequent year. Fungal Ecology 15:73-81 DOI 10.13039/501100000040.

Wang Q, Garrity GM, Tiedje JM, Cole JR. 2007. Naive Bayesian classifier for rapid assignment of rRNA sequences into the new bacterial taxonomy. Appl Environ Microbiol 73(16): 5261-5267. DOI 10.1128/AEM.00062-07.

Weinert N, Meincke R, Gottwald C, Radl V, Dong X, Schloter M, Berg G, Smalla K. 2010. Effects of genetically modified potatoes with increased zeaxanthin content on the abundance and diversity of Rhizobacteria with in vitro antagonistic activity do not exceed natural variability among cultivars. Plant Soil 326:437-452 DOI 10.1007/s11104-009-0024-Z.

Weinert N, Piceno Y, Ding GC, Meincke R, Heuer H, Berg G. 2011. PhyloChip hybridization uncovered an enormous bacterial diversity in the rhizosphere of di $\square$ rent potato cultivars: many common and few cultivar-dependent taxa. FEMS Microbiology 
698

699

700

701

702

703

704

705

706

707

708

709

710

711

712

713

714

715

716

717

718

719

720

721

722

723

Ecology 75:497-506 DOI 10.1111/j.1574-6941.2010.01025.x.

Wintera M, Mol FD, Tiedemann AV. 2014. Cropping systems with maize and oilseed rape for energy production may reduce the risk of stem base diseases in wheat. Field Crops Research 156:249-257 DOI 10.1016/j.fcr.2013.10.009.

Xu L, Ravnskov S, Larsen J, Nilsson RH, Nicolaisen M. 2012. Soil fungal community structure along a soil health gradient in pea fields examined using deep amplicon sequencing. Soil Biolology \& Biochemistry 46:26-32 DOI 10.1016/j.soilbio.2011.11.010.

Zhalnina K, Louie KB, Hao Z, Mansoori N, da Rocha UN, Shi S, Cho H, Karaoz U, Loqué D, Bowen BP, Firestone MK, Northen TR, Brodie EL. 2018. Dynamic root exudate chemistry and microbial substrate preferences drive patterns in rhizosphere microbial community assembly. Nature Microbiology 3(4):470-480 DOI 10.1038/s41564-018-0129-3.

Zhang Q, Stummer BE, Guo Q, Zhang W, Harvey PR. 2021. Quantification of pseudomonas protegens fd6 and bacillus subtilis ncd-2 in soil and the wheat rhizosphere and suppression of root pathogenic rhizoctonia solani ag-8. Biological Control 154: 104504. DOI 10.1016/j.biocontrol.2020.104504.

Zhang R, Vivanco JM, Shen Q. 2017. The unseen rhizosphere root-soil-microbe interactions for crop production. Current Opinion in Microbiology 37: 8-14. DOI 10.1016/j.mib.2017.03.008.

Zhang R, Vivanco JM, Shen Q. 2017. The unseen rhizosphere root-soil-microbe interactions for crop production. Current Opinion in Microbiology 37:8-14 DOI 10.1016/j.mib.2017.03.008.

Zhang X, Yu D, Wang H. 2021. Pepper root rot resistance and pepper yield are enhanced $t$ hrough biological agent G15 soil amelioration. PeerJ 9:e11768 DOI

10.7717/peerj.11768. 


\section{Figure 1}

\section{Sampling plots of wheat root.}

This picture mainly shows the readers the serious situation of the root rot disease in the wheat field of Xiangyang Original Farm. After the occurrence of wheat root rot disease, the ears of wheat is becoming abnormal white, and even false ripening in advance. Judging by this phenotype, when the roots of wheat plants were dug out, it was observed that the diseased roots were unusually brown, dark brown, and even black compared to the healthy roots. These diseased roots can lead to plant death at a later stage, leading to crop failure.

A The occurrence of wheat root rot in this wheat field in 2015 and 2016. This land has a total of 3 acres, and 17 plots have been set up to test the efficacy of wheat root rot. The disease index of the wheat root rot reached 43\%. B The soil sample collection of wheat root in this wheat field in 2017. Areas with diseased wheat and healthy wheat were marked by inserting white cards at fixed points. The samples, in April and May, were collected from the areas labeled in April. 


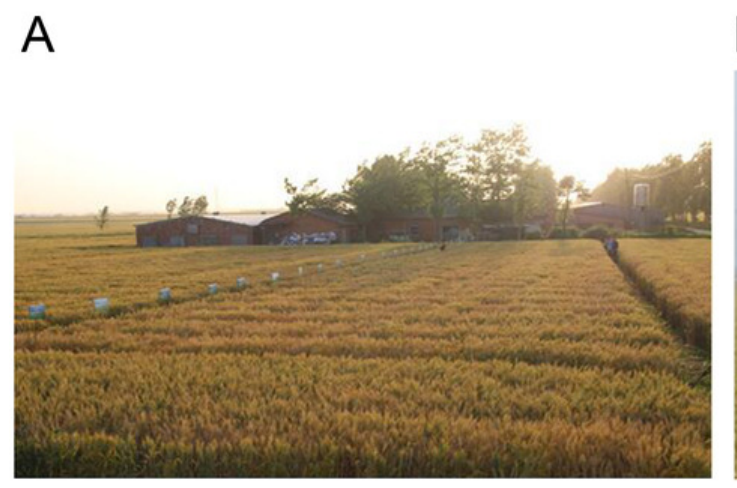

B

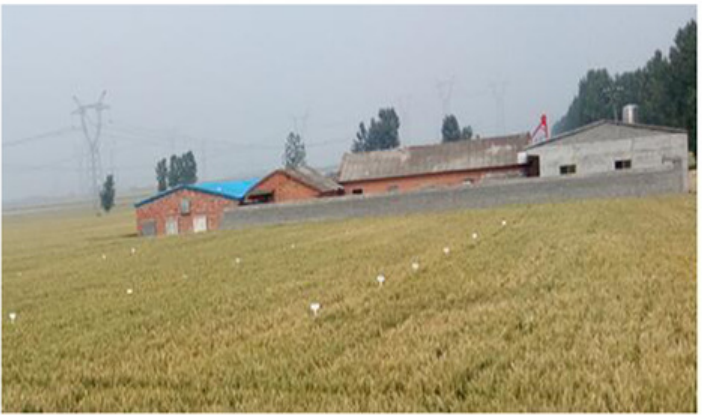


Figure 2

Comparative analysis of OTUs and genus levels in each community.

A Principal coordinate analysis (PCOA) at the OTU level in healthy and diseased groups at the heading stage and filling stage. Distance algorithm is based on bray_curtis. B Sample hierarchical clustering analysis based on OTU level. C Typing analysis of fungi at the genus level. 
A

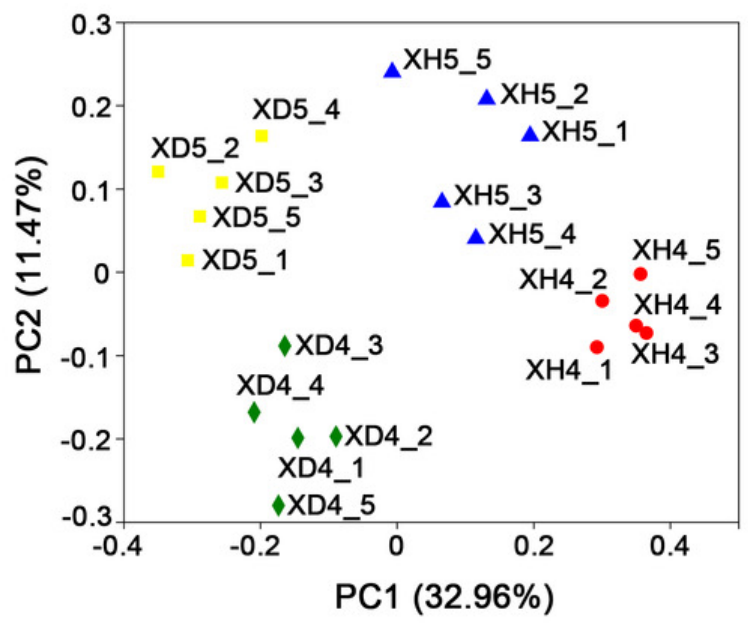

C

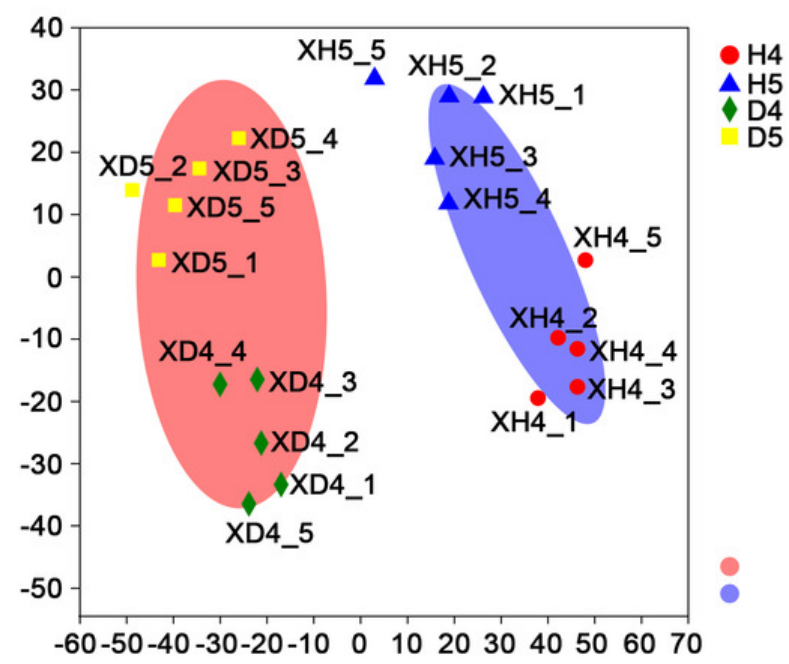

B

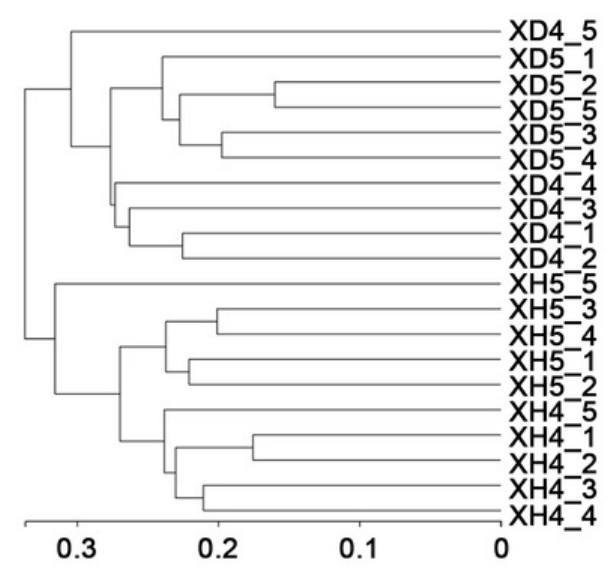




\section{Figure 3}

Species composition analysis.

A Percent community abundance at the phylum level in each groups. B Species abundance clustering at genus level in each sample. C Circos representation showing distribution of genus with significant difference in abundance in different groups. D Analysis of common and endemic genera in the different populations by Venn diagram. 
A
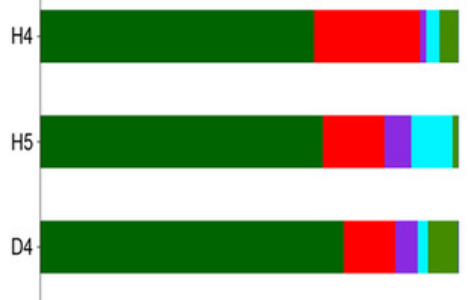

D5

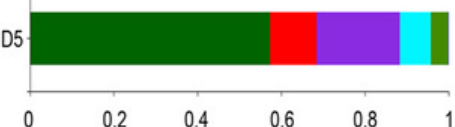

- Ascomycota

- Basidiomycota

- unclassified_k_Fungi

Zygomycota

Chytridiomycota

- others

B
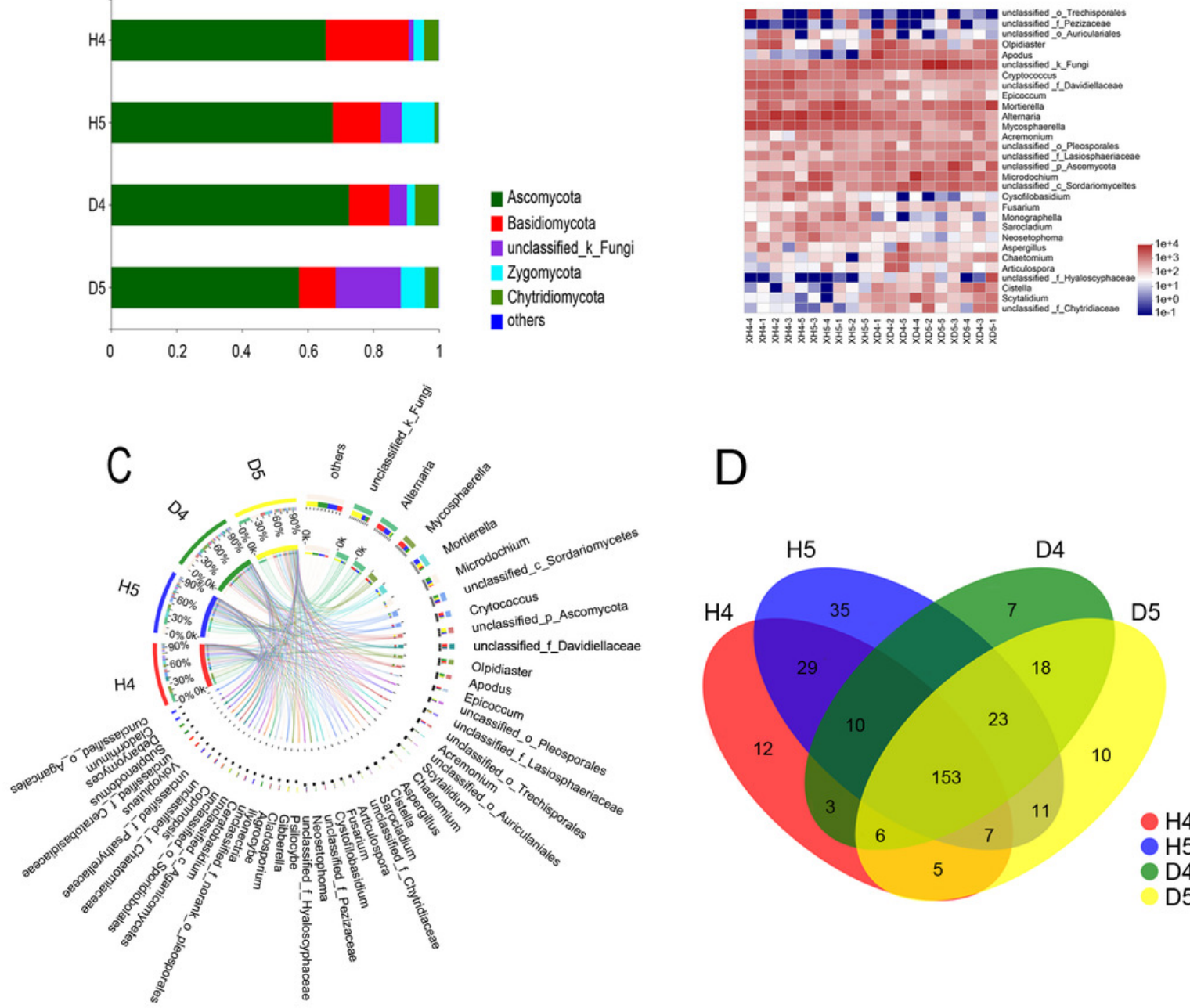

D

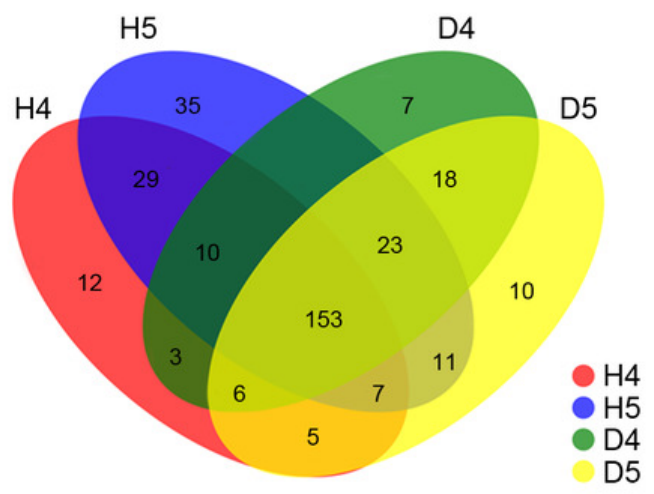


Figure 4

Hierarchical clustering analysis at the OTU level between physical and chemical soil properties and the 30 most abundant genera. 


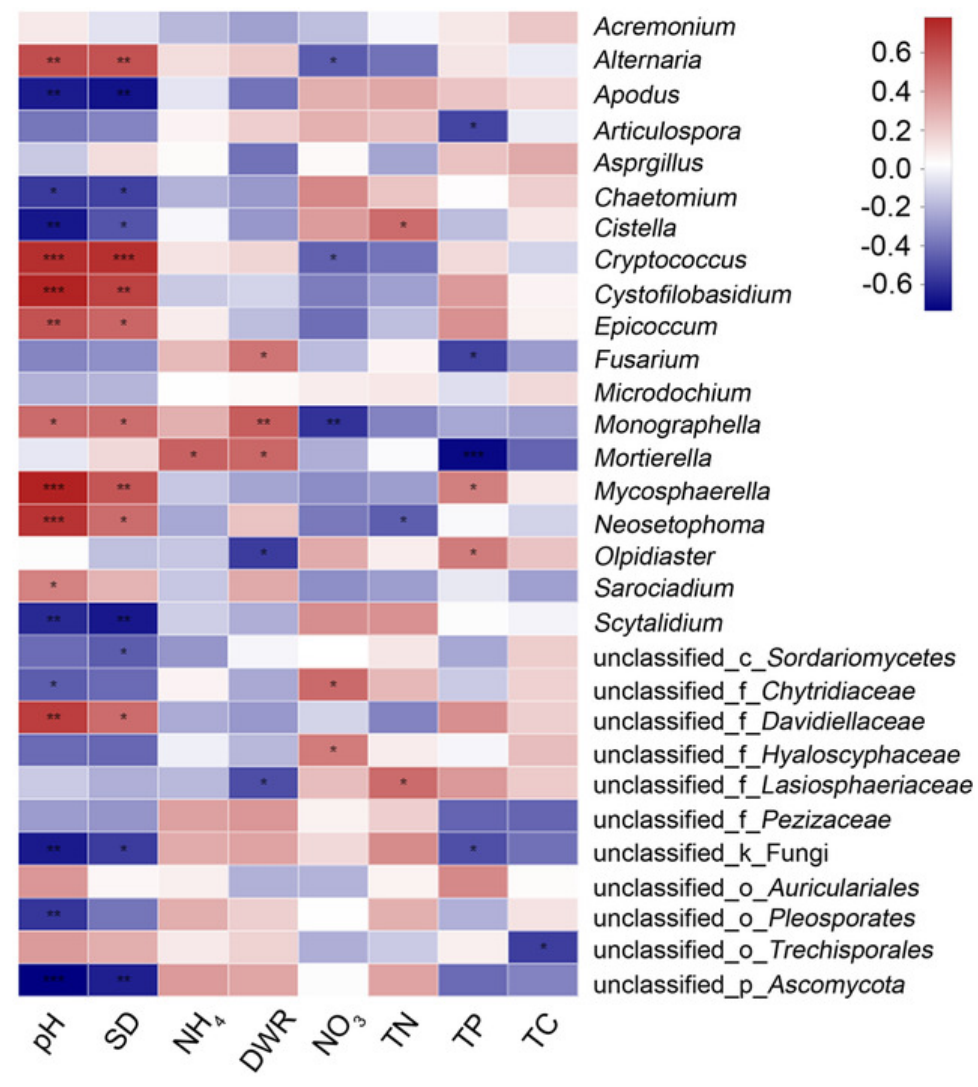




\section{Table $\mathbf{1}$ (on next page)}

The analysis of alpha diversity index in healthy and diseased groups. 
1 Table 1

\begin{tabular}{|c|l|l|l|l|l|}
\hline Sample\Estimators & Sobs & Ace & Chao & Shannon & Coverage \\
\hline H4 & 129.40 & 142.21 & 142.14 & 3.03 & 0.9994 \\
\hline D4 & 135.60 & 154.71 & 149.52 & 3.37 & 0.9995 \\
\hline H5 & 163.40 & 178.98 & 180.19 & 3.41 & 0.9993 \\
\hline D5 & 155.80 & 160.04 & 161.46 & 3.32 & 0.9997 \\
\hline
\end{tabular}

2 
Table 2 (on next page)

All fungi with a richness greater than one percent in each group. There are 30 genera in the four groups, which mainly belong to Ascomycota, Basidiomycota, and Chytridiomycota. 
Table 2

\begin{tabular}{|c|c|c|c|c|c|}
\hline Phylum & Genus & $\mathrm{H} 4$ & D4 & $\mathrm{H} 5$ & D5 \\
\hline \multirow[t]{20}{*}{ p_Ascomycota } & $g \_$Microdochium & 0.0184 & 0.0760 & 0.0455 & 0.0454 \\
\hline & g_Apodus & 0.0010 & 0.0662 & 0.0035 & 0.0314 \\
\hline & g___Mycosphaerella & 0.1291 & 0.0460 & 0.0609 & 0.0136 \\
\hline & g_Scytalidium & 0.0005 & 0.0309 & 0.0027 & 0.0168 \\
\hline & g_Chaetomium & 0.0028 & 0.0295 & 0.0029 & 0.0132 \\
\hline & g_Alternaria & 0.1489 & 0.0284 & 0.1160 & 0.0288 \\
\hline & g_Aspergillus & 0.0119 & 0.0274 & 0.0021 & 0.0035 \\
\hline & $g$ __Articulospora & 0.0012 & 0.0271 & 0.0044 & 0.0045 \\
\hline & g_Cistella & 0.0010 & 0.0236 & 0.0015 & 0.0164 \\
\hline & g_Acremonium & 0.0103 & 0.0213 & 0.0165 & 0.0081 \\
\hline & g__Epicoccum & 0.0442 & 0.0160 & 0.0201 & 0.0057 \\
\hline & g___Subplenodomus & 0.0005 & 0.0134 & 0.0009 & 0.0001 \\
\hline & $g$ __Debaryomyces & 0.0008 & 0.0108 & 0.0001 & 0.0003 \\
\hline & $g$ __Sarocladium & 0.0193 & 0.0055 & 0.0127 & 0.0042 \\
\hline & g_Fusarium & 0.0021 & 0.0050 & 0.0197 & 0.0100 \\
\hline & g_Gibberella & 0.0122 & 0.0036 & 0.0083 & 0.0038 \\
\hline & $\begin{array}{l}g \_ \text {Cladosporium } \\
\end{array}$ & 0.0135 & 0.0027 & 0.0103 & 0.0013 \\
\hline & $g \quad$ Neosetophoma & 0.0106 & 0.0025 & 0.0195 & 0.0008 \\
\hline & g__Monographella & 0.0114 & 0.0003 & 0.0259 & 0.0015 \\
\hline & $g \quad$ Ilyonectria & 0.0025 & 0.0001 & 0.0210 & 0.0005 \\
\hline
\end{tabular}




\begin{tabular}{|c|c|c|c|c|c|}
\hline & g_Cladorrhinum & 0.0000 & 0.0000 & 0.0118 & 0.0000 \\
\hline \multirow[t]{7}{*}{ p_Basidiomycota } & g_Agrocybe & 0.0000 & 0.0255 & 0 & 0.0006 \\
\hline & g_Cryptococcus & 0.0726 & 0.0102 & 0 & 0.0161 \\
\hline & g_Ceratobasidium & 0.0009 & 0.0022 & 0 & 0.0109 \\
\hline & g_Psilocybe & 0.0049 & 0.0013 & 0 & 0.0214 \\
\hline & g_Volvopluteus & 0.0156 & 0.0011 & 0 & 0.0001 \\
\hline & g_Cystofilobasidium & 0.0319 & 0.0009 & 0 & 0.0003 \\
\hline & g_Coprinopsis & 0.0113 & 0.0006 & 0 & 0.0001 \\
\hline \multirow[t]{2}{*}{ p_Chytridiomycota } & g_olpidiaster & 0.0432 & 0.0529 & 0 & 0.0128 \\
\hline & g__Mortierella & 0.0315 & 0.0244 & 0 & 0.0737 \\
\hline
\end{tabular}

2 


\section{Table 3 (on next page)}

The physical and chemical properties of the rhizosphere.

*TP: total phosphorus, $\mathrm{NH}_{4}$ : ammonium nitrogen, $\mathrm{NO}_{3}$ : nitrate nitrogen, $\mathrm{TN}$ : total nitrogen, $\mathrm{SD}$ : soil density , TC: total carbon, DHR: soil dry-humidity ratio. 
1 Table 3

\begin{tabular}{|l|l|l|l|l|l|l|l|l|}
\hline Sample ID & $\mathrm{TP}$ & $\mathrm{NH}_{4}$ & $\mathrm{NO}_{3}$ & $\mathrm{TN}$ & $\mathrm{pH}$ & $\mathrm{SD}$ & $\mathrm{TC}$ \\
\hline $\mathrm{H} 4$ & $4.16 \pm 0.13$ & $16.02 \pm 3.27$ & $26.38 \pm 6.03$ & $204.1 \pm 30.94$ & $7.18 \pm 0.06$ & $2.68 \pm 0.06$ & $9.82 \pm 1.37$ & $86.26 \pm 1.32$ \\
\hline $\mathrm{D} 4$ & $4.13 \pm 0.21$ & $14.04 \pm 2.62$ & $30.97 \pm 5.95$ & $251.48 \pm 21.09$ & $6.95 \pm 0.08$ & $2.42 \pm 0.05$ & $10.56 \pm 2.25$ & $85.15 \pm 0.84$ \\
\hline $\mathrm{H} 5$ & $3.82 \pm 0.18$ & $17.45 \pm 4.20$ & $23.48 \pm 2.23$ & $217.65 \pm 49.43$ & $7.15 \pm 0.07$ & $2.5 \pm 0.03$ & $7.93 \pm 0.71$ & $89.77 \pm 0.32$ \\
\hline D5 & $3.84 \pm 0.16$ & $18.71 \pm 2.41$ & $29.38 \pm 3.82$ & $237.39 \pm 52.74$ & $6.76 \pm 0.15$ & $2.48 \pm 0.03$ & $8.54 \pm 0.43$ & $88.77 \pm 0.21$ \\
\hline
\end{tabular}

2 